\title{
Use of intracervical Foley catheter for pre-induction cervical ripening in women planned for vaginal birth after previous caesarean section
}

\author{
Sheenam Jakhar*, Veena Ganju Malla
}

Department of Obstetrics and Gynaecology, Atal Bihari Vajpayee Institute of Medical Sciences and Dr. Ram Manohar Lohia hospital, New Delhi, India

Received: 28 July 2020

Revised: 06 November 2020

Accepted: 07 November 2020

\section{*Correspondence:}

Dr. Sheenam Jakhar,

E-mail: sheenam7jakhar@gmail.com

Copyright: (c) the author(s), publisher and licensee Medip Academy. This is an open-access article distributed under the terms of the Creative Commons Attribution Non-Commercial License, which permits unrestricted non-commercial use, distribution, and reproduction in any medium, provided the original work is properly cited.

\section{ABSTRACT}

Background: Vaginal birth after previous caesarean section is challenging for obstetricians due to increased risk of uterine rupture. Common methods for labour induction in post caesarean pregnancies are membrane sweeping, balloon catheters, prostaglandins ( $\left.\mathrm{PGE}_{2}\right)$, and oxytocin. As currently available data is limited, the evidence of safest method of induction is lacking. The present study aimed to assess the effectiveness of intra-cervical Foley catheter for pre-induction cervical ripening in women planned for vaginal birth after caesarean section.

Methods: This prospective cross-sectional study included 24 pregnant women with a history of previous caesarean section, admitted for induction of labour. Induction was performed in patients with unfavourable modified Bishop Score by intra-cervical Foley catheter. The change in modified Bishop Score, oxytocin requirement, inductiondelivery interval, mode of delivery, maternal complications and neonatal outcome were observed.

Results: There was significant improvement in modified BS noted at the end of trans-cervical Foley catheter induction and this improvement in mean of modified BS was observed to be statistically significant $(\mathrm{p}<0.0001)$. The vaginal delivery rate was $29.2 \%$ while $70.8 \%$ of patients underwent caesarean section. No significant maternal or foetal complications were observed with Foley catheter induction except for one case of vaginal bleeding. There was no case of intrapartum or postpartum maternal infection.

Conclusions: Foley catheter may be a cheap and effective method for pre-induction cervical ripening and induction of labour in patients with previous caesarean section.

Keywords: Bishop score, Elective repeat caesarean delivery, Induction of labour, Trial of labour after caesarean, Vaginal birth after caesarean section

\section{INTRODUCTION}

Caesarean section (CS) rate is high and continues to rise in both developed and developing countries which is a cause of concern for the world. According to the recent National Family Health Survey-4 (NFHS-4) which was conducted in 2017, the average rate of CS in India is 17.2 percent ranging from 5.8 percent in Nagaland to 58.0 percent in Telangana. ${ }^{1}$ There is an increase of 16.7 per cent in the CS rates annually in India which is one of the highest among the countries. ${ }^{2}$
An increase in the rate of primary CS, is one of the main reason for rising cesarean delivery rate as previous CS has been the most common indication for caesarean delivery. ${ }^{3}$ Women with a previous CS can either undergo elective repeat caesarean delivery (ERCD) or vaginal birth after caesarean section (VBAC) and are at increased risk of complications in their subsequent pregnancies. ${ }^{4}$ Although, there are risks in both, yet the current clinical practice guidelines support VBAC as an alternative to reduce $\mathrm{CS}$ rates and related morbidities. ${ }^{5}$ 
Induction of labour (IOL) is a common obstetric intervention required in one out of four term pregnancies. $^{6}$ The greatest concern following IOL in previous $\mathrm{CS}$ is the risk of uterine scar rupture with subsequent catastrophic maternal and neonatal outcome. It has been estimated that nearly one-quarter of women who were candidates for trial of labour after caesarean (TOLAC) required IOL. ${ }^{8}$ The success rate for all patients attempting VBAC ranges from 60 to 85 percent. $^{9}$

Various mechanical and pharmacological methods have been used for cervical priming and IOL in women with prior CS, but the randomized control trials (RCT) evidence on the safest method of induction is inadequate and studies are underpowered to detect clinically relevant differences for many outcomes. Data is mostly limited to findings from retrospective studies of fair to poor quality. Mechanical methods apply pressure on the internal cervical os, stretch the lower uterine segment and increase local production of prostaglandin which induces the cervical ripening without inducing any uterine contractions. These include a transcervical Foley catheter, bougies, hygroscopic laminaria tents and forewater amniotomy. The pharmacological methods include prostaglandins, $\left(\mathrm{PGE}_{1}\right.$ and $\mathrm{PGE}_{2}$ ) oxytocin, oestrogens, mifepristone, etc. The externally administered prostaglandins are effective at the cervical ripening and hasten the delivery, but they increase the risk of the uterine hyperstimulation and produce foetal heart rate (FHR) changes. ${ }^{8}$

The cervical ripening effect of the Foley catheter, which has been most widely used, is as good as that of the $\mathrm{PGE}_{2}$ gel in women with a previous one CS. It has lower risk of systemic and serious side effects like uterine hyperstimulation and rupture, since increased risk of uterine rupture is a major concern during IOL in women with previous $\mathrm{CS}$. ${ }^{4,9-12}$

Also, the attention should be drawn towards carrying out aseptic measures while Foley catheter is being inserted, to avoid maternal and probable neonatal infections. ${ }^{13}$

With the renewed interest in the effectiveness of intracervical Foley catheter for IOL, the current study was undertaken to assess the effectiveness of intracervical Foley catheter for pre-induction cervical ripening in women planned for VBAC.

\section{METHODS}

This prospective cross-sectional study was undertaken in the Department of Obstetrics and Gynaecology, Atal Bihari Vajpayee Institute of Medical Sciences and Dr. Ram Manohar Lohia hospital, New Delhi from November 2017 to March 2019. Twenty-four pregnant women who satisfied the inclusion and exclusion criteria, were included in the study after obtaining a written informed consent from the patient.

\section{Inclusion criteria}

The inclusion criteria were previous one uneventful lower segment caesarean section, singleton term pregnancy with cephalic presentation, unfavourable cervix (Modified Bishop score <6) and an adequate pelvis. ${ }^{14}$

\section{Exclusion criteria}

Women with multiple pregnancy, history of complication during previous CS and puerperium, ante-partum haemorrhage, recurring indication for $\mathrm{CS}$, previous classical CS and pre-mature rupture of membranes were excluded from the study.

Each patient was assessed for individual risks and likelihood of successful vaginal birth and those, willing to undergo VBAC, were enrolled in the study. The selected patients were assessed in detail about the history of the present pregnancy, menstrual history, obstetric history with special regards to details of previous CS, past medical or surgical, personal and socio-economic history. A detailed history of previous CS was noted including indication of CS, period of gestation at CS, any antenatal, intra-natal and post-natal complications. The period of gestation for the current pregnancy was estimated by the last menstrual period (LMP) and the earliest ultrasound parameters, if LMP was not known. A complete general physical, systematic and obstetric examination was performed. Informed consent for TOLAC and IOL was taken from each subject and induction was done after term whenever indicated with use of intra-cervical Foley catheter. Patients admitted for IOL with Foley catheter had an initial assessment of modified Bishop score (BS) and cardiotocography (CTG) at the time of admission.

After explaining about the procedure and emptying the bladder, patients were placed in dorsal position. Sim's speculum was introduced, cervix was cleaned with povidone-iodine, and anterior lip of the cervix was held with sponge holding forceps. A sterile 16 French Foley catheter was introduced into the endocervical canal under all aseptic precautions. Balloon was inflated with $30 \mathrm{cc}$ (cubic-centimetre) of normal saline and pulled against the internal OS of the cervix. The catheter was strapped to the inner thigh with gentle traction and at the completion of the procedure, FHR was auscultated and CTG tracing was obtained. The catheter was checked for its position and the traction four hourly.

After 12 hours of insertion, Foley catheter was removed unless expelled spontaneously, modified BS and status of membranes was assessed. Artificial rupture of membranes (ARM) and oxytocin augmentation, if required, was done when uterine contractions had initiated. In the absence of uterine contractions after 12 hours of Foley's removal, labour induction was done with oxytocin, followed by ARM, whenever needed. To induce effective uterine contractions (3-4 contractions in 
10 minutes lasting for 40-50 seconds), oxytocin infusion was used with the dose of 2 milliunits/minute, and was increased by $2 \mathrm{mU} /$ minute every 30 minutes as per the requirement, maximum up to $16 \mathrm{mU} /$ minute. Labour was followed as per standard hospital labour protocol till the time of delivery. The primary outcome was to assess the change in the modified BS. The secondary outcomes assessed were mode of delivery, induction to delivery interval, intra-partum events like non-reassuring FHR, uterine tachysystole, rupture of membrane and neonatal outcome.

Normality of data was tested by Kolmogorov-Smirnov test. If the normality was rejected then non parametric test was used. Statistical tests were applied as follows: 1) Quantitative variables were compared using Wilcoxon signed rank test was used for comparison of pre and post bishop score. 2) Qualitative variables were correlated using Chi-Square test/Fisher's exact test.

\section{RESULTS}

In the study population of a total of 24 subjects, the mean age was $28.5 \pm 3.39$ years. Majority of subjects $(62.5 \%)$ were in the age group of 26-30 years.

Table 1: Descriptive data of study subjects.

\begin{tabular}{|lll|}
\hline Patient characteristics & Sample size & Mean \pm SD \\
\hline Age $($ years) & 24 & $28.5 \pm 3.39$ \\
\hline Height $(\mathbf{c m})$ & 24 & $159.04 \pm 6.98$ \\
\hline Weight $(\mathbf{k g})$ & 24 & $65.17 \pm 9.19$ \\
\hline BMI $\left(\mathbf{k g} / \mathbf{m}^{\mathbf{2}}\right)$ & 24 & $25.71 \pm 3.11$ \\
\hline $\begin{array}{l}\text { Inter-conceptional } \\
\text { period (years) }\end{array}$ & 24 & $4.83 \pm 1.58$ \\
Mean gestational age & 24 & $39.04 \pm 0.62$ \\
\hline
\end{tabular}

In most of the study subjects $(91.67 \%)$, previous CS was performed due to an emergency indication whereas in the rest $(8.33 \%)$, the surgical procedure was an elective lower segment caesarean section (LSCS). All the study subjects had previous CS done for non-recurring cause, the most common indication being foetal distress. While other indications were failed induction, meconium stained liquor and oligohydramnios, breech presentation, big baby, cord around neck, second stage arrest and transverse lie.

In the study population, pre-induction cervical ripening was done with the intra-cervical Foley catheter in all subjects with unfavourable cervix as per indication and the catheter was left in-situ for 12 hours. Spontaneous expulsion was observed in 14 study subjects $(58.33 \%)$ after a mean interval of 8.3 hours while it was removed by manual deflation after 12 hours in 10 subjects $(41.46 \%)$.

Modified BS was measured at the time of Foley catheter insertion and spontaneous expulsion or immediately after removal. The modified BS was observed to be ranging from $0-4$ at the start of Foley catheter induction while it was 3-8 at the end of induction.

There was significant improvement in the modified BS observed at the end of Foley catheter induction. The mean of modified BS measured at the start of Foley induction was $2.67 \pm 0.96$, while on spontaneous expulsion or at the end of 12 hours of insertion, it was $5.38 \pm 1.24$ (Table 2). This improvement in the mean of modified BS was observed to be statistically significant with $\mathrm{p}$ value $<0.0001$.

\section{Table 2: Pre and post induction modified Bishop score.}

\begin{tabular}{|lllll|}
$\begin{array}{l}\text { Bishop } \\
\text { score }\end{array}$ & Mean \pm SD & Median & Min-max & P value \\
\hline O hours & $2.67 \pm 0.96$ & 3 & $0-4$ & \multirow{2}{*}{$<0.0001$} \\
\hline 12 hours & $5.38 \pm 1.24$ & 5.5 & $3-8$ & \\
\hline
\end{tabular}

Patients were further augmented with oxytocin infusion and ARM as per protocol and the observations were recorded.

Among the 24 subjects, seven $(29.16 \%)$ had vaginal delivery while rest of the 17 patients $(70.83 \%)$ underwent CS. The course of labour was analysed in 17 study subjects who underwent CS for various indications. Out of these, seven subjects went into active labour following study protocol but still had to be terminated by CS due to maternal tachycardia (2), foetal distress (3), and active phase arrest (2). From the remaining 10 patients, eight went into labour but did not progress to active phase, and were terminated by CS due to maternal tachycardia (2) and foetal distress (6). One patient underwent CS following APH soon after Foley removal before further oxytocin augmentation and ARM could be done. One patient did not initiate labour despite oxytocin and ARM.

Among the seven subjects who had vaginal birth, all received oxytocin augmentation. While ARM was needed in 5 subjects, two patients had spontaneous rupture of membranes. The mean duration of oxytocin infusion given as per protocol was 15.64 hours.

Table 3: Indications of emergency caesarean section.

\begin{tabular}{|ll|}
\hline Indications of emergency LSCS & Percentage \\
\hline Ante-partum haemorrhage & $5.88 \%$ \\
\hline Failed induction & $5.88 \%$ \\
\hline Foetal distress & $52.90 \%$ \\
\hline Maternal tachycardia & $23.53 \%$ \\
\hline Arrest of labour & $11.76 \%$ \\
\hline
\end{tabular}

Previous scar was observed during CS per-operatively in all 17 subjects. Previous scar was intact in 12 patients $(70.59 \%)$ while it was thinned out in 5 study subjects only. (29.41\%). Maternal and neonatal complications are mentioned in the table below (Table 4). 
Table 4: Maternal and neonatal complications.

\begin{tabular}{|c|c|}
\hline \multicolumn{2}{|l|}{ Maternal complications } \\
\hline Uterine rupture & 0 \\
\hline Meconium stained liquor & 2 \\
\hline Uterine hyperstimulation & 0 \\
\hline Vaginal bleeding & 1 \\
\hline $\mathrm{PPH}$ & 0 \\
\hline Maternal death & 0 \\
\hline \multicolumn{2}{|l|}{ Post-partum infection } \\
\hline Wound gaping & 0 \\
\hline Pyrexia & 0 \\
\hline \multicolumn{2}{|l|}{ Neonatal outcomes } \\
\hline Birth weight varied from & $2.42-3.41 \mathrm{~kg}$ \\
\hline \multicolumn{2}{|l|}{ Neonatal complications } \\
\hline Stillbirth & 0 \\
\hline Early neonatal death & 0 \\
\hline
\end{tabular}

\section{DISCUSSION}

VBAC is a contribution towards bringing down the CS rate and reducing the maternal morbidity and mortality. TOLAC is a relatively safe procedure, but it is not risk free and should be attempted with caution. Women who have previously delivered by CS have subsequent successful vaginal delivery rates of $50-85 \% .{ }^{15-21}$ The BS at the time of insertion varied from $0-4$ and increased to $3-8$, at the time of Foley catheter removal. There was an increase of more than 3 points in BS in $54.16 \%$ of subjects. Median value for BS was four at the time of removal of Foley. Thus, there was statistically significant improvement in the modified BS observed with Foley catheter induction with the mean BS improving from $2.67 \pm 0.96$ to $5.38 \pm 1.24$ thereby suggesting Foley catheter to be an effective pre-induction cervical ripening agent in pregnancy with previous CS. This was comparable with the study by Hemalatha et al, who observed statistically significant improvement in the BS ranging from 2 to 5 at the time of Foley insertion to $4-10$ at the time of removal. $^{22}$

The vaginal delivery was observed to be $29.17 \%$ in the current study while rest $(70.83 \%)$ of the subjects underwent CS. Twenty three percent of subjects who underwent CS had threatened scar rupture as assessed by maternal tachycardia and could have been avoided as three out of four subjects were found to have intact scar intra-operatively. Patients who had CS in view of foetal distress $(52 \%)$ had distress from causes not related to Foley induction. The mean induction-delivery interval (IDI) for vaginal birth in the present study was 22.8 hours and was comparable to a study by Ziyauddin et al, Hemalatha et al, and Meetei et al, who documented IDI to be 23 hours, 18.5 hours and 27.5 hours respectively. ${ }^{10,22,23}$

In the present study, 17 out of 24 patients underwent emergency LSCS. The CS rate in our study was substantially higher $(70.8 \%)$ than reported in other studies for IOL in women with previous LSCS, in which
CS rates of 39 to $49 \%$ have been reported. ${ }^{5,23}$ In the study by Hemalatha et al, out of 30 patients among the study group, $40 \%$ women underwent CS for various indications. ${ }^{22}$ In the study done by Gonsalves et al, out of 68 study subjects, emergency CS were performed in $30.9 \%$ females, due to failure to progress $(52.4 \%)$, nonreassuring fetal status $(42.9 \%)$ and cord prolapse $(4.8 \%) .^{25}$

In our study group, there was no case of uterine rupture. This is in agreement with the induction done with Foley catheter by Sananes et al. ${ }^{26}$ Studies done by Hemalatha et al, Gonslaves et al, Ben-Aroya et al and also reported no case of uterine rupture. ${ }^{22,25,27}$ In the present study, there were no cases of uterine hypertonicity and tachysystole. This is in agreement with the study done by Ziyyaudin et al, Hemalatha et al and Gonsalves et al. ${ }^{10,22,25}$ In the present study population of 24 subjects, only one case of vaginal bleeding was observed and emergency LSCS was done. In the study done by Gonzalves et al, out of 68 study subjects, 4 women experienced vaginal bleeding following the insertion of the Foley catheter; 3 had minimal bleeding and subsequently underwent a successful VBAC, but one had heavy vaginal bleeding and foetal bradycardia, resulting in an emergency CS. ${ }^{25}$ There was no case of intrapartum or postpartum maternal infection observed in the present study. A recent systematic review has also suggested that Foley catheter is not associated with an increased risk of infectious morbidity. ${ }^{28}$ It was concluded by a large cohort study also that in women with a previous caesarean section, IOL is an effective and safe option and labour induction with balloon catheter does not result in a significant increase in adverse maternal and neonatal outcome as compared with planned caesarean section. ${ }^{29}$ The pre-induction cervical ripening with Foley catheter may be a simple, safe and effective option in pregnancies with previous CS.

\section{CONCLUSION}

As number of women undergoing $\mathrm{CS}$ is increasing worldwide, VBAC can contribute towards bringing down the CS rate. The pre-induction cervical ripening with Foley catheter may be a simple, safe and effective option in these cases. The current study was underpowered by its small sample size and further large sample size randomized clinical trials are needed for evidence-based recommendations.

\section{ACKNOWLEDGMENTS}

Authors would like to express their gratitude to all the study subjects and to the department of Obstetrics and Gynaecology, Atal Bihari Vajpayee Institute of Medical Sciences and Dr. Ram Manohar Lohia Hospital, New Delhi for their cooperation and support.

Funding: No funding sources

Conflict of interest: None declared 
Ethical approval: The study was approved by the Institutional Ethics Committee

\section{REFERENCES}

1. Radhakrishnan T, Vasanthakumari KP, Babu PK. Increasing trend of caesarean rates in India: evidence from NFHS-4. J Med Sci Clin Res. 2017;5(8):2616776.

2. Stanton CK, Holtz SA. Levels and trends in cesarean birth in the developing world. Stud Fam Plan. 2006;37(1):41-8.

3. HKCOG Territory-wide $\mathrm{O}$ and $\mathrm{G}$ Audit Report: Caesarean section. Hong Kong: Hong Kong College of Obstetricians and Gynaecologists; 2009. Available at: http://www.hkcog.org.hk/hkcog/pages_3_77.html.

4. Birth after previous Caesarean birth. RCOG Green-top Guideline No. 45. Royal College of Obstetricians and Gynaecologists; 2007.

5. American College of Obstetrics and Gynaecologists. Vaginal birth after caesarean delivery. ACOG Practice bulletin no. 115. Obstet Gynecol. 2010;116:450-63 .

6. Talaulikar VS, Arulkumaran S. Failed induction of labor: strategies to improve the success rates. Obstet Gynecol Survey. 2011;66(11):717-28.

7. Kaczmarczyk M, Sparen P, Terry P, Cnattingius S. Risk factors for uterine rupture and neonatal consequences of uterine rupture: a population-based study of successive pregnancies in Sweden. BJOG. 2007;114(10):1208-14.

8. Kelly AJ, Malik S, Smith L, Kavanagh J, Thomas J. Vaginal prostaglandin (PGE2 and PGF2 $\alpha$ ) for induction of labour at term. Cochrane Database Syst Rev. 2009;4:CD003101.

9. Scott JR. Intrapartum management of trial of labour after caesarean delivery: evidence and experience. BJOG. 2014;121(2):157-62

10. Ziyauddin F, Hakim S, Beriwal S. Transcervical Foley catheter versus the vaginal prostaglandin E2 gel in the induction of labour in a previous one caesarean sectiona clinical study. J Clin Diagnost Res. 2013;7:1400-3 .

11. 1Locatelli A, Regalia AL, Ghidini A, Ciriello E, Biffi A, Pezzullo JC. Risks of induction of labour in women with a uterine scar from previous low transverse caesarean section. BJOG. 2004;111(12):1394-9.

12. Jozwiak M, Dodd JM. Methods of term labour induction for women with a previous caesarean section. Cochrane Database Syst Rev. 2013;(3):CD009792.

13. Salva S, Nadeem FZ, Alfia Z, Rahat NQ. Increased risk of cervical canal infections with intracervical Foley catheter. J Coll Physicians Surg Pak. 2003;13(3):146-9.

14. Misra R. Ian Donald's Practical Obstetric Problem, 7th Edition. BI Publications Pvt. Ltd; 2014.

15. Society of Obstetricians and Gynaecologists of Canada. Vaginal birth after previous Caesarean birth. Clinical
Practice Guideline No. 68. Ottawa (ON): SOGC; December 1997.

16. Biswas A. Management of previous cesarean section. Curr Opin Obstet Gynecol. 2003;15(2):123-9.

17. Flamm BL, Urn OW, Jones C, Fallon D, Newman LA, Mantis K. Vaginal birth after cesarean section: results of a multicenter study. Am J Obstet Gynecol. 1988;158:1079-84.

18. Quilligan EJ. Vaginal birth after Cesarean section: 270 degrees. J Obstet Gynaecol Res. 2001;27(4):169-73.

19. Scott JR. Avoiding labor problems during vaginal birth after caesarean delivery. Clin Obstet Gynecol. 1997;40:533-41.

20. Rageth C, Juzi C, Grossenbacher H. Delivery after previous Caesarean: a risk evaluation. Obstet Gynecol. 1999;93:332-7.

21. Lovell R. Vaginal delivery after caesarean section: factors influencing success rates. Aust NZ J Obstet Gynaecol. 1996;36:4-8.

22. Hemalatha KR, Swetha D. Case series of Foley's induction in patients with previous caesarean. Int $\mathbf{J}$ Reprod Contracept Obstet Gynaecol. 2017;6(4):163538.

23. Meetei LT, Suri V, Aggarwal N. Induction of labor in patients with previous caesarean section with unfavourable cervix. J Med Soc. 2014;28:29-33.

24. Scott JR. Intrapartum management of trial of labour after caesarean delivery: evidence and experience. BJOG. 2014;121(2):157-62.

25. Gonsalves H, Al-Riyami N, Al-Dughaishi T, Gowri V, Al-Azri M, Salahuddin A. Use of Intracervical Foley catheter for induction of labour in cases of previous caesarean section: experience of a single tertiary centre in Oman. Sultan Qaboos Univ Med J. 2016;16(4):e44550.

26. Sananes N, Rodriguez M, Stora C, Pinton A, Fritz G, Gaudineau A, et al. Efficacy and safety of labour induction in patients with a single previous caesarean section: a proposal for a clinical protocol. Arch Gynecol Obstet. 2014;290(4):669-76.

27. Ben-Aroya Z, Hallak M, Segal D, Friger M, Katz M, Mazor M. Ripening of the uterine cervix in a postcesarean parturient: prostaglandin E2 versus Foley catheter. J Matern fet Neonat Med. 2002;12(1):42-5.

28. McMaster K, Sanchez-Ramos L, Kaunitz AM. Evaluation of a transcervical Foley catheter as a source of infection: a systematic review and meta-analysis. Obstet Gynecol. 2015;126:539-51.

29. Huisman CM, Ten Eikelder ML, Mast K, Oude Rengerink K, Jozwiak M, van Dunné F, et al. Balloon catheter for induction of labor in women with one previous cesarean and an unfavorable cervix. Acta Obstet Gynecol Scand. 2019;98(7):920-8.

Cite this article as: Jakhar S, Malla VG. Use of intracervical Foley catheter for pre-induction cervical ripening in women planned for vaginal birth after previous caesarean section. Int J Reprod Contracept Obstet Gynecol 2020;9:4927-31. 